\title{
Semantic Derogation in Persian Animal Proverbs
}

\author{
Azam Estaji \\ Ferdowsi University of Mashhad, Iran \\ Email: Estaji@um.ac.ir \\ Fakhteh Nakhavali* \\ Ferdowi University of Mashhad, Iran \\ Email: Fakhteh_Nakhavaly@yahoo.com
}

\begin{abstract}
In this paper the analysis of Persian animal proverbs is studied based on the semantic - cognitive frame. The main aim of this research is to determine if there is semantic derogation in Persian, and if there is, ascertain whether it applies equally to both sexes (male \& female) terms. The analysis shows that sex and semantic derogation are not shown in Persian structures and proverbs as much as other languages, but in the cases with semantic derogation, the metaphorical meanings of the female proverbs connote worse qualities than those connoted by the male proverbs.
\end{abstract}

Index Terms - semantic derogation, animal metaphor, proverb, sexist language

\section{INTRODUCTION}

For most people metaphor is a device of the poetic imagination, a matter of extraordinary language, metaphor is characteristic of language alone but figurative expressions are not just word combinations. The metaphorical proverb is a structure that shows one thing is inferred to another by an implicit comparison (Lakoff and Johnson, 1980, p.3).

This investigation is based on two theoretical sources. On the one hand, the studies of Fontecha and Catalan (2003) related to the analysis of semantic derogation and sexism in languages; on the other hand the views of Lakoff and Johnson (1980) on metaphor, in their view "metaphor" is understanding and experiencing one thing in terms of another.

According to Fontecha and Catalan (2003), sexism and semantic derogation are viewed in most languages, and in most cases the worst qualities are connoted to female terms rather than to male terms, so in most languages of the world, there are some aspects of semantic derogation and semantic imbalance.

In this study, the focus is on Persian proverbs and analyzing those which referred to a special sex.

\section{REVIEW OF LITERATURE}

Researches on animal expressions are rare, and this kind of expressions are mainly represented in dictionaries, however the works of some researchers on animal expressions are presented as follow.

Nesi (1995) discussed the figurative meanings to the names of different animals in different cultures, and highlights some of the problems language learners and translators face when dealing with single - word conventional metaphor. This research shows that many common terms such as "cat", "cow", and "mouse" were found to have a wide range of figurative meanings and discussions with informants revealed that even advanced learners tend to think in terms of the connotations of their first culture when they encounter or use these words in a figurative sense in English.

Nadim (2000) examines animal roles in Shirazi proverbs with an approach to sociolinguistics. After analyzing about 100 animal expressions, he concludes that donkey expressions are the most frequent ones and have some salient semantic molecules such "crazy, worthless, and absurd".

Hsieh (2001) Studied the origins, constructions, meanings and applications of the animal metaphors in Chinese and German. This study also included the ways of thinking and the cultural particularities of the respective societies as implied in the metaphors.

Hsieh (2003) represented a study which contained 2980 Mandarin Chinese and 2630 German written and spoken animal expressions. Animal expressions in that corpora included: metaphors, similes, proverbs, sayings, frozen collocations, grammatically ill-formed collocations and routine formulae. Hsieh analyzed the semantic functions of animal names, the concepts of them, and the applications of the corpora in both languages.

Halupka - Resetar and Radic (2003) dealt with combined metaphorical / vocative uses of animal names in Serbian in addressing people, both abusively an affectionately, so expressing the speakers' attitude towards their addressee. This research is based on the results obtained in a survey conducted with 100 university linguistics students.

Fontecha and Catalan (2003) presented a contrastive cognitive analysis of metaphorical usages of the word pairs fox / vixen and bull / cow together with their Spanish counterparts to find out whether animal metaphors are conceptualized

\footnotetext{
* Corresponding Author
} 
in English and Spanish equally, and to show some kind of semantic derogation appears in both languages and the main metaphorical meanings of the female terms connote worse qualities than those connoted by the metaphors of the male terms. And there are differences in the degree and kind of semantic derogation in both languages.

Hsieh (2004) represented a paper in which the results of a cross - lingual study of Mandarin Chinese corpus and German Corpus of fixed animal expressions were presented. She examined the underlying conceit and also the metaphorical tenors of the expressions in both languages. She discussed the proportions of different types of underlying conceits and the salient metaphorical tenors they convey and the positive and negative tenors which shows animal expressions are the vocabulary of values.

Hsieh (2005) presented a corpus based study to explore the functions and concepts of the life form animal expression in Chinese and German, and aim to explore the semantic and pragmatic function of the wild animal names in the light of the underlying conceit.

Hsieh (2006) studied the corpora of animal expression in Chinese and German. She applied Goddard's (1998) approach of semantic molecules to examine "cat" expressions to explore the semantic interaction and the cultural backgrounds in the form of society.

Hsieh (2007) explored the origins, lexical changes, and meanings of dragon lexemes in Mandarin Chinese. She found that the dragon plays an important role for the Chinese and it is a mythical creature. After the lexical change was examined, the study focused on the semantic development of long lexemes, and the Chinese values, they convey.

Hsieh (2008) Compared animal and plant metaphors in order to show the semantic autonomy of language and the cognitive level of using these metaphors. She found that metaphors are not scientific, but the essence of metaphors and nature overlap, and animal metaphors are active and plant metaphors are static expressions.

\section{MethodolOGY}

In this study a semantic - pragmatic analysis is applied which fascilate the organizing of animal concepts and metaphors in Persian. For gathering the data, a wide variety of dictionaries have been used, spoken data are gathered from daily conversation and questionnaires. The reasons for using dictionaries for date gathering instead of other sources was availability of dictionaries and literature in libraries, book shops, and institutions, and also dictionaries compiled the words, expressions, meanings, and definitions, so they are proper sources for semantic analysis.

In this study 1771 Persian animal expressions were analyzed and only few of them showed some aspects of semantic derogation.

Semantic derogation is technically defined as a change of meaning (Fontecha and Catalan, 2003, p.773) but in this research it refers to words that convey negative, demeaning or sexual connotations.

\section{ANALYSIS}

In this section the meanings of the Persian proverbs with semantic derogation will be studied. As it was mentioned before semantic imbalance is not revealed in Persian animal expressions as much as other languages, so the data of this section is few and limited to 20 cases which most of them refer to semantic derogation against female.

This section is divided in to two parts. In the first one, the Persian proverbs with semantic derogation against female, and in the second one the proverbs with semantic derogation against male, will be studied. The analysis, description, and concepts of these proverbs will be represented as follow.

\section{A. Persian Proverbs with Semantic Derogation against Female}

The analysis of Persian proverbs show that some animal expressions include "donkey", "dog", "camel", "hen", and "rooster" expressions reveal some aspects of semantic imbalance against female.

In this section the analysis of these expressions will be represented according to the frequency of animal names in Persian proverbs.

1. semantic derogation in "donkey" expressions

"Donkey" expressions are the most frequent Persian expressions, and show most semantic derogation in this language too. Analysis of the data shows that some proverbs as follow reveal some aspects of semantic imbalance against female:

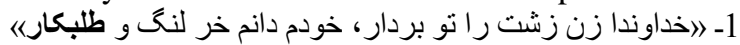

"Cheeky \& lame donkey know I, take you the ugly woman God" (L.T)1

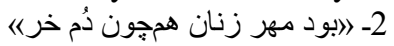

"Donkey tail like woman affection is" (L.T)

3-3 إهوه شترى، غمزه خركى

"Like a donkey wink, like a camel coquetry" (L.T)

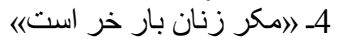

"Is donkey load women cunning" (L.T)

The first proverb means "having an ugly wife is worse and more difficult than having a troublesome donkey".

\footnotetext{
${ }^{1}$-Literal Translation
} 
The second proverb means "the women love and affection is like the donkey's tail": it is something worthless and instable.

The third proverb means "to coquet like camel and donkey". In Persian "camel" is known as a careless and gawky animal, and "donkey" as a thoughtless and heedless one. In this proverb the names of these animals accompany with the noun "coquettishness" and "amorous glance" which are just used for female. In the other words, in this proverb the negative the negative adjectives of these two animals are attributed to women, and used to describe a woman with inelegant behavior.

The fourth proverb means "The donkey is carrying the women's cunning".

In this proverb women are revealed a cunning beings who trick naïve and foolish guys.

As it is seen in the mentioned proverbs, concepts of "unaffectionate \& unfeeling", "difficulty in tolerating an ugly woman", "having inelegant and careless behavior", and "craft and tricky" are attributed to females within Persian proverbs.

2. semantic derogation in "dog" expressions

After "donkey" expressions, "dog" expressions are most frequent ones in Persian in which there are some aspects of semantic imbalance as follow.

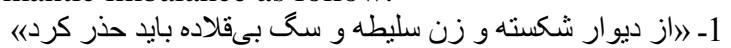

"Avoid should collar without dog and shrew woman and broken wall from" (L.T)

《)

"Is collar without dog shrew woman" (L.T)

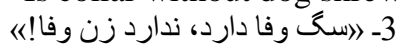

"Loyalty woman doesn't have, has loyalty the dog" (L.T)

4- اوفا از زن مخو اه از سخ وفا جوى

"Look for loyalty dog from, don't ask woman from loyalty" (L.T)

The first proverb means "you should avoid the broken wall, shrew woman and a dog without collar". It means that, bad - tempered woman is more dangerous and tormenting than a wall which is broken or a dog without collar.

The second proverb means "a shrew woman is like a dog without collar" in this proverb again the adjective of the animal (cruelty and ill humor) are attributed to females.

The third proverb means "dog" has loyalty, but not the woman", this proverb compares woman with "dog" to show women are more unfaithful than the dogs.

The fourth proverb means "never ask a woman for loyalty, but ask it from a "dog" this proverb again describes women as unfaithful beings and know it a mistake to ask it from them.

As it seems 'shrew, cruelty, and unfaithfulness' are attributed to women through "dog" expressions in Persian.

3. Semantic derogation in "camel" expressions

The third frequent animal expressions in Persian are "camel" expressions.

1- (عشوه شترى، غمزه خركى (Like a donkey wink, like a camel coquetry) (L.T)

which was explained before, and

2- 《به شتر كفتند غمزهكن، زدو پِاليز را خراب كرد (Break down the patch and hit, do wink say they the camel to) (L.T)

As it is mentioned before, winking and coquetting are just used for women, so here the carelessness of "camel" is attributed to females with inattentive behavior.

4. Semantic derogation in "hen" expressions

"Hen" expressions are the most frequent bird expressions in Persian, and the names of ""hen" and "rooster" are the only names of animals which distinguish sexes in Persian. In the other words, "hen" expressions only refer to female and "rooster" expressions only refer to male.

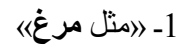

"Hen like" (L.T)

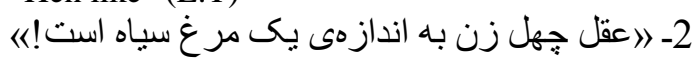

"Is black hen a to equal woman forty intelligence" (L.T)

The first proverb means "like a hen" 2 is used to refer to a fat and sleepy woman who usually goes to sleep soon.

The second proverb means "The intelligence of 40 women is equal to a single black hen!" . This proverb wants to show that women are stupid and dull beings.

As the analysis of "hen" expressions show through these expressions women are described as "fat, sleepy, stupid, and dull" guys.

In the next section the Persian proverbs with semantic derogation against male will be given.

\section{B. Persian Proverbs with Semantic Derogation against Male}

As it is mentioned before the number of proverbs with semantic derogation against male are much fewer than the proverbs with semantic derogation against female, and only in 4 Persian proverbs there are aspects of semantic derogation against male as follow.

2 - a according to the proverb dictionary definition, means: "being fat and sleepy" (Dehkhoda, 1982, p.10) 


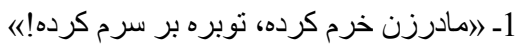

"Wear my head on nose - bag make me donkey mother in law" (L.T)

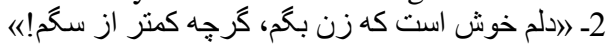

"Dog from more inferior although call woman that I am delighted" (L.T)

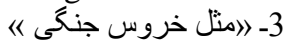

"Quarrelsome rooster like" (L.T)

4- 》(مثل خروس《)

"Rooster like" (L.T)

The first proverb means "My mother in law supposes me a donkey and causes me to wear a nose - bag!" this proverb shows the mother in law (female) as a cunning guy and the groom as a stupid one, so there is semantic derogation against both sexes, but more against the male.

The second proverb means "I'm delighted to call my wife, although I'm inferior than a dog!". As it seems in this proverb there is semantic derogation against men, because compares male with dog (which is considered as an inferior, worthless animal in some Persian proverbs), and knows men more inferior than this animal.

The third proverb means "like a quarrelsome rooster". As it is mentioned before all the "rooster" expressions refer to male, so the adjective come from the "rooster" name will be attributed to male too.

The fourth proverb means "like a rooster" is another Persian proverb which a attribute the "rooster" characteristic of "voluptuousness" to men.

So the analysis of the Persian proverbs with semantic derogation shows that "stupidity, worthlessness, being quarrelsome" can be attributed to male and make semantic imbalance.

In the following table the abstract of these analysis will be given.

TABLE 1

THE PERSIAN PROVERBS WITH SEMANTIC DEROGATION

\begin{tabular}{|c|c|c|}
\hline $\begin{array}{l}\text { Animal names used } \\
\text { in these proverbs }\end{array}$ & $\begin{array}{l}\text { Persian proverbs with semantic derogation } \\
\text { against female }\end{array}$ & $\begin{array}{l}\text { Persian proverbs with semantic } \\
\text { derogation against male }\end{array}$ \\
\hline "donkey" & 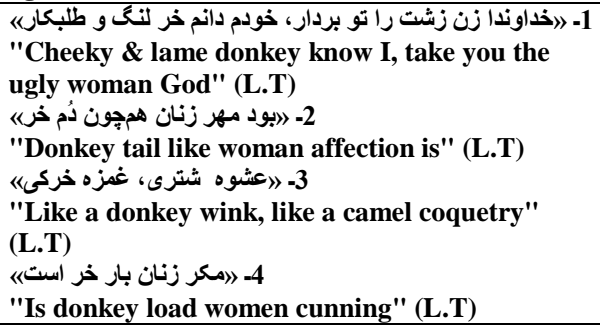 & $\begin{array}{l}\text { "مادرزن خرم كرده، توبره بر سرم كرده!" } \\
\text { "Wear my head on nose - bag make } \\
\text { me donkey mother in law" (L.T) }\end{array}$ \\
\hline "dog" & 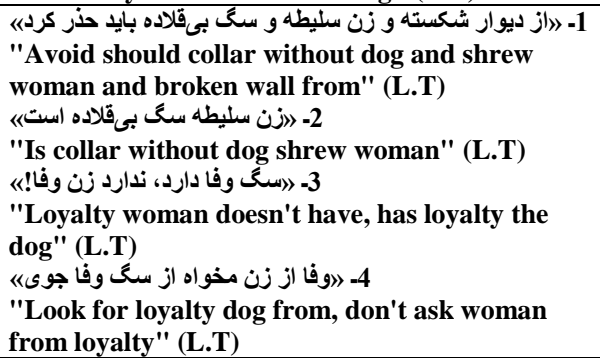 & 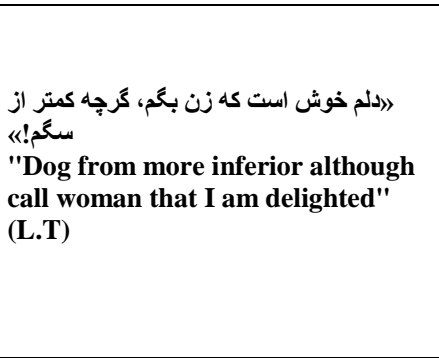 \\
\hline "camel" & 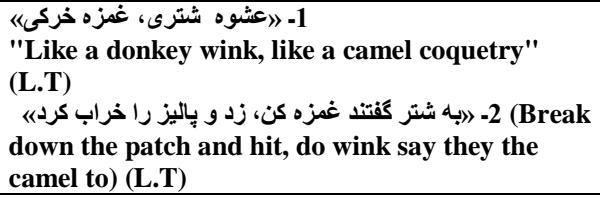 & \\
\hline "hen" & 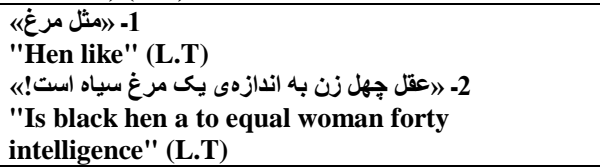 & \\
\hline "rooster" & & 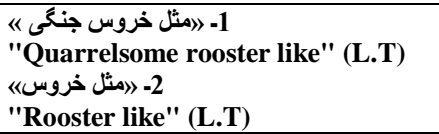 \\
\hline
\end{tabular}

\section{CONCLUSION}

The semantic-pragmatic analysis of the Persian proverbs shows that:

1. Some Persian animal metaphors are conceptualized.

2. There is difficulty of characterizing each feature as positive or negative. 
3. There is difficulty in ranging the degree of negative features.

4. Sexism and semantic derogation are not revealed in Persian expressions as much as other languages.

5. Most of the time animal pairs with different sexes are called with a single name in Persian.

6. Analysis of Persian proverbs show that if semantic imbalance exist in animal expressions, most of the time used to refer to female rather than to male.

7. "Hen" and "rooster" expressions are the only animal expressions which show sexism in Persian and refer to a special sex.

\section{REFERENCES}

[1] Dehkhoda, Ali akbar. (1982). "The selected proverbs". (2nd ed.). Tirazhe publication: Tehran.

[2] Fontecha, Almudena Fernandez \& Rosa Maria Jimenez Catalan. (2003). "Semantic derogation in animal metaphor: a Contrastive - Cognitive analysis of two male / female examples in English and Spanish". Journal of pragmatics, 35: 771-797.

[3] Halupka - Resetar, Sabina \& Biljana Radic. (2003). "Animal names used in addressing people in Serbian". Journal of pragmatics, 35: 1891-1902.

[4] Hsieh, shelley C- Y. (2005). "life Form concepts: Animal Expressions in Mandarin Chinese and German". Journal of Southern Taiwan University of Technology, 30: 185-200.

[5] Hsieh, shelley Ching-Yu. (2008). "Cognitive Models of Using Animal and plant Metaphors, NCKU FLLD Monograph series vol.1, language across cultures, National Cheng kung University.

[6] Hsieh, Shelley C-Y. (2001). "A Semantic and Sociolinguistic Study of Animal Metaphor in Mandarin Chinese and German". Comparative Linguistics, National Cheng Kung University, Taiwan.

[7] Hsieh, Shelley C-Y. (2003). "The corpora of Mandarin Chinese and German animal expressions". Southern Taiwan University of Technology.

[8] Hsieh, Shelley C-Y. (2004). "The corpora of Mandarin Chinese and German animal fixed expressions". Department of Applied English, Southern Taiwan University of Technology, Taiwan, R.O.C.

[9] Hsieh, shelley C-Y. (2006). "A corpus-based study on animal expressions in Mandarin Chinese and German". Journal of pragmatics, 38: 2206-2222.

[10] Hsieh, shelley C-Y. (2007). "A Diachronic Study of Dragon Lexemes in Mandarin Chinese: Lexical Change and semantic Development", Intergrams 8.1, http: // benz. nchu.edu.Tw/ intergrams / 081/081-hsieh.pdf.

[11] Lakoff, George \& Johnson, Mark. (1980). Metaphors we live by. University of Chicago press, Chicago.

[12] Nadim, Mostafa. (2000). "The role of animals in Shirazi proverbs with sociolinguistic approach. (1st ed.). first volume. Daneshgah publication: Tehran.

[13] Nesi, Hilary. (1995). "A modern bestiary: a contrastive study of the figurative meanings of animal terms". ELT Journal, 49: 272-278.

[14] Shakourzadeh, Ebrahim. (1993). "Ten thousand Persian proverbs". (1st ed.). Astane ghods publication: Tehran.

Azam Estaji is associate professor in General Linguistics. She is currently in Ferdowsi university of Mashhad, where she teaches phonology, phonetics, research, and the school of linguistics. She published a lot of articles in different journals. Her major interest is: discourse analysis and historical linguistics.

Fakhteh Nakhavali is an MA graduate student of General Linguistics. She has done her study in Ferdowsi university of Mashhad. Her major interests are: discourse analysis and historical linguistics. 